\title{
Prognostic value of parameters derived from white blood cell and differential counts in patients receiving palliative radiotherapy
}

\author{
TETSUO SAITO $^{1}$, RYO TOYA ${ }^{1,2}$, TOMOHIKO MATSUYAMA ${ }^{1}$, \\ AKIKO SEMBA $^{1}$, KEIYA MATSUYAMA ${ }^{1}$ and NATSUO OYA ${ }^{1}$ \\ ${ }^{1}$ Department of Radiation Oncology, Kumamoto University Hospital, Kumamoto 860-8556, Japan; \\ ${ }^{2}$ Department of Human Oncology, University of Wisconsin School of Medicine and Public Health, Madison, WI 53705, USA
}

Received April 8, 2016; Accepted June 27, 2016

DOI: $10.3892 / \operatorname{mco} .2016 .965$

\begin{abstract}
The aim of the present study was to identify white blood cell (WBC) parameters with high prognostic value for the survival of patients receiving palliative radiotherapy. The prognostic value of seven parameters derived from WBC and differential counts was retrospectively evaluated in patients who underwent palliative radiotherapy between October, 2010 and June, 2013. The analyzed parameters were the total WBC count, the absolute and relative lymphocyte count, the absolute and relative neutrophil count, and the neutrophil-to-lymphocyte and lymphocyte-to-monocyte ratios. Following univariate analysis, multivariate Cox regression analysis was performed to adjust for gender, age, disease type, previous chemotherapy, previous radiotherapy and the levels of albumin and lactate dehydrogenase. A total of 220 patients with a median survival of 4.7 months were identified. All seven parameters were found to be statistically significant predictors of survival on univariate Cox regression analysis $(\mathrm{P}<0.05)$. Of these parameters, the low relative lymphocyte and high relative neutrophil counts were consistent predictors of poor survival in patients who received chemotherapy within 1 month prior to blood sampling $(n=68)$ and in patients who received steroid treatment at the time of sampling $(n=49)$. Multivariate Cox regression analysis revealed that the relative lymphocyte and neutrophil counts were independent predictors of survival in all 220 patients $(\mathrm{P}<0.05)$. In conclusion, relative lymphocyte and neutrophil counts were of high prognostic value for the survival of patients receiving palliative radiotherapy, even in those receiving medications that affect $\mathrm{WBC}$ and differential counts.
\end{abstract}

Correspondence to: Dr Tetsuo Saito, Department of Radiation Oncology, Kumamoto University Hospital, 1-1-1, Honjo, Chuo-ku, Kumamoto-shi, Kumamoto 860-8556, Japan

E-mail: tsaito@kumamoto-u.ac.jp

Key words: palliative radiotherapy, prognostic factor, overall survival, white blood cell parameters, prediction of survival

\section{Introduction}

The prediction of survival is crucial for determining the indications for radiotherapy (RT) and the dose fractionation schedule $(1,2)$. Although various patient and tumor characteristics have been investigated for their prognostic value in patients receiving palliative RT (3-5), predicting prognosis remains a challenge $(1,6)$.

Cancer-related inflammation affects the proliferation and survival of malignant cells, angiogenesis, tumor metastasis, the subversion of adaptive immunity and the tumor response to chemotherapeutic drugs and hormones $(7,8)$. Parameters derived from white blood cell (WBC) and differential counts have been reported to be powerful prognostic predictors in patients with malignant and non-malignant diseases (9-11). The total WBC count (TWBC) (12), absolute lymphocyte count (ALC) (13-15), relative lymphocyte count (RLC) $(12,13,16)$, absolute neutrophil count (ANC) $(13,17,18)$, relative neutrophil count (RNC) $(13,19)$, the neutrophil-to-lymphocyte ratio (N/L ratio) $(13,20-22)$ and the lymphocyte-to-monocyte ratio (L/M ratio) (22-24) have been identified as significant prognostic factors in patients with malignant diseases. As the majority of these studies only evaluated one or a few of these parameters (12,14-24), their comparative assessment in patients undergoing palliative RT is required.

To identify WBC parameters with high prognostic value for the survival of patients receiving palliative RT, parameters derived from WBC and differential counts were retrospectively compared and subgroup analysis was performed to investigate the prognostic value of these parameters in patients on medication affecting their WBC count.

\section{Patients and methods}

Patients. This retrospective study was approved by the Kumamoto University Hospital Institutional Review Board (no. 986), and patient informed consent was waived due to the retrospective nature of the study. The inclusion criteria for this study were as follows: i) Patients treated with palliative RT between October, 2010 and June, 2013; ii) acquisition of laboratory data, including WBC and differential counts and albumin and lactate dehydrogenase (LDH) levels, within 2 weeks prior to the initiation of RT; and iii) availability of 
chemotherapy data obtained within 1 month prior to blood sampling and of data on medications administered at the time of blood sampling. When more than one blood sample was obtained within 2 weeks prior to the initiation of RT, the latest sample was used for analysis. Patient, tumor and treatment data were collected from medical charts.

Prognostic factors of survival. Seven parameters, namely $\mathrm{TWBC}, \mathrm{ALC}, \mathrm{RLC}, \mathrm{ANC}, \mathrm{RNC}, \mathrm{N} / \mathrm{L}$ ratio and $\mathrm{L} / \mathrm{M}$ ratio, were analyzed. The TWBC, RLC, and RNC were available from the patients' medical charts; the other 4 parameters were calculated based on these counts.

Statistical analysis. Data were summarized using descriptive statistics (frequency, percentage, median and range). Overall survival, calculated from the initiation of RT, was estimated using the Kaplan-Meier method; differences were assessed using the log-rank test. For this test, continuous variables were dichotomized based on our laboratory's reference values. Univariate Cox regression analysis was performed, first to assess the effect of the WBC parameters on the overall survival of all patients, and then on patients receiving medications that affect WBC and differential counts: The patients who had received chemotherapy within 1 month prior to blood sampling (subgroup A) and those who received steroids at the time of blood sampling (subgroup B). Finally, the parameters that were statistically significant predictors of survival in all patients and in the two subgroups, were subjected to multivariate analysis. Multivariate Cox regression analysis was performed to adjust for gender, age, disease type, previous chemotherapy, previous RT and albumin and LDH levels. For univariate and multivariate Cox regression analysis, the seven WBC parameters, age, and albumin and LDH levels, were used as continuous variables. Receiver operating characteristic (ROC) analysis was performed in patients who were followed up for $>5$ months or until death. The prognostic value of the WBC parameters for death within 5 months was evaluated using the area under the curve (AUC) of the ROC curves. Differences of $\mathrm{P}<0.05$ were considered to indicate statistically significant differences. All statistical analyses were performed using SPSS software, version 22 (IBM SPSS, Armonk, NY, USA).

\section{Results}

Patients. A total of 220 patients with a median survival of 4.7 months (95\% confidence interval: 3.7-5.7 months) were identified. The median follow-up period from the initiation of RT was 3.5 months (range, 0-53.5 months) for all patients. The patient characteristics and laboratory data are summarized in Table I. In 189 patients $(86 \%)$ with solid tumors, the primary site was the lung $(n=59)$, digestive tract $(n=40)$, liver $(n=10)$ and other sites $(n=80)$. A total of 31 patients $(14 \%)$ had hematological tumors; 16 presented with multiple myeloma, 9 with malignant lymphoma and 6 with other diseases. The median total radiation dose was $30 \mathrm{~Gy}$ (range, 3-60 Gy) and the median number of fractions was 10 (range, 1-30).

Prognostic factors for survival. In all 220 patients, univariate Cox regression analysis revealed that all seven WBC parameters were statistically significant predictors of survival
Table I. Patient characteristics and laboratory data $(n=220)$.

\begin{tabular}{|c|c|c|}
\hline Characteristics & No. of patients & $\%$ \\
\hline Male gender & 139 & 63 \\
\hline \multicolumn{3}{|l|}{ Age (years) } \\
\hline Median & 67 & \\
\hline Range & $20-86$ & \\
\hline \multicolumn{3}{|l|}{ Type of malignancy } \\
\hline Solid & 189 & 86 \\
\hline Hematological & 31 & 14 \\
\hline Previous chemotherapy & 150 & 68 \\
\hline Previous radiotherapy & 82 & 37 \\
\hline \multicolumn{3}{|l|}{ Albumin (g/dl) } \\
\hline Median & 3.4 & \\
\hline Range & $1.6-4.8$ & \\
\hline \multicolumn{3}{|l|}{ LDH (U/l) } \\
\hline Median & 249.5 & \\
\hline Range & $79-6,500$ & \\
\hline \multicolumn{3}{|l|}{ TWBC $\left(x 10^{9} / 1\right)$} \\
\hline Median & 6.520 & \\
\hline Range & $1.700-70.500$ & \\
\hline \multicolumn{3}{|l|}{$\operatorname{ALC}\left(\times 10^{9} / 1\right)$} \\
\hline Median & 1.066 & \\
\hline Range & $0.110-3.969$ & \\
\hline \multicolumn{3}{|l|}{$\operatorname{RLC}(\%)$} \\
\hline Median & 16.0 & \\
\hline Range & $1.3-55.9$ & \\
\hline \multicolumn{3}{|l|}{$\operatorname{ANC}\left(\times 10^{9} / 1\right)$} \\
\hline Median & 4.693 & \\
\hline Range & $0.656-68.174$ & \\
\hline \multicolumn{3}{|l|}{ RNC (\%) } \\
\hline Median & 74.4 & \\
\hline Range & 29.4-96.7 & \\
\hline \multicolumn{3}{|l|}{$\mathrm{N} / \mathrm{L}$ ratio } \\
\hline Median & 4.68 & \\
\hline Range & $0.57-74.35$ & \\
\hline \multicolumn{3}{|l|}{$\mathrm{L} / \mathrm{M}$ ratio } \\
\hline Median & 2.54 & \\
\hline Range & $0.35-30.93$ & \\
\hline
\end{tabular}

LDH, lactate dehydrogenase; TWBC, total white blood cell count; ALC, absolute lymphocyte count; RLC, relative lymphocyte count; ANC, absolute neutrophil count; RNC, relative neutrophil count; N/L ratio, neutrophil-to-lymphocyte ratio; L/M ratio, lymphocyte-to-monocyte ratio.

(Table II). A low RLC and high RNC were consistent predictors of poor survival in the two subgroups (Table II). Multivariate Cox regression analysis revealed that RLC and RNC were independent predictors of survival in all 220 patients $(\mathrm{P}<0.05$, Table III).

Survival curves were compared using the log-rank test (Fig. 1). The continuous variables were dichotomized 
Table II. Univariate Cox regression analyses for overall survival.

\begin{tabular}{|c|c|c|c|c|c|c|c|c|c|}
\hline \multirow[b]{2}{*}{ Variables } & \multicolumn{3}{|c|}{ All patients $(n=220)$} & \multicolumn{3}{|c|}{ Subgroup $A^{a}(n=68)$} & \multicolumn{3}{|c|}{ Subgroup $B^{b}(n=49)$} \\
\hline & $\mathrm{HR}$ & $95 \% \mathrm{CI}$ & P-value & HR & $95 \% \mathrm{CI}$ & P-value & $\mathrm{HR}$ & $95 \% \mathrm{CI}$ & P-value \\
\hline TWBC (per increase of $\left.1 \times 10^{9} / 1\right)$ & 1.05 & $1.03-1.07$ & $<0.001$ & 1.05 & $0.97-1.14$ & 0.217 & 1.02 & $0.99-1.05$ & 0.114 \\
\hline ALC (per increase of $\left.1 \times 10^{9} / 1\right)$ & 0.55 & $0.40-0.74$ & $<0.001$ & 0.68 & $0.44-1.06$ & 0.090 & 0.68 & $0.42-1.10$ & 0.120 \\
\hline RLC (per 1\% increase) & 0.95 & $0.93-0.96$ & $<0.001$ & 0.97 & $0.95-0.99$ & 0.005 & 0.95 & $0.91-0.99$ & 0.007 \\
\hline ANC (per increase of $\left.1 \times 10^{9} / 1\right)$ & 1.05 & $1.03-1.07$ & $<0.001$ & 1.06 & $0.99-1.15$ & 0.116 & 1.02 & $0.99-1.05$ & 0.085 \\
\hline RNC (per $1 \%$ increase) & 1.04 & $1.03-1.05$ & $<0.001$ & 1.02 & $1.00-1.03$ & 0.021 & 1.04 & $1.01-1.07$ & 0.010 \\
\hline N/L ratio (per increase of 1 ) & 1.02 & $1.01-1.03$ & 0.002 & 0.99 & $0.98-1.02$ & 0.944 & 1.00 & $0.99-1.02$ & 0.707 \\
\hline $\mathrm{L} / \mathrm{M}$ ratio (per increase of 1 ) & 0.84 & $0.77-0.91$ & $<0.001$ & 0.96 & $0.89-1.04$ & 0.350 & 0.99 & $0.92-1.06$ & 0.715 \\
\hline
\end{tabular}

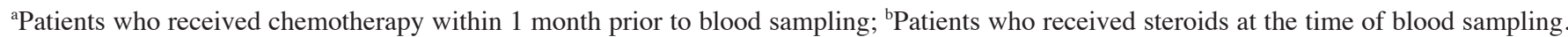
TWBC, total white blood cell count; ALC, absolute lymphocyte count; RLC, relative lymphocyte count; ANC, absolute neutrophil count; RNC, relative neutrophil count; N/L ratio, neutrophil-to-lymphocyte ratio; L/M ratio, lymphocyte-to-monocyte ratio; HR, hazard ratio; CI, confidence interval.

Table III. Multivariate Cox regression analyses for overall survival in all patients $(n=220)$.

\begin{tabular}{llll}
\hline A, RLC & & & \\
\hline Variables & HR & $95 \%$ CI & P-value \\
\hline Male vs. female gender & 0.86 & $0.62-1.21$ & 0.387 \\
Age (per 1 year increase) & 1.02 & $1.00-1.03$ & 0.028 \\
Hematological vs. solid tumors & 0.64 & $0.37-1.10$ & 0.104 \\
Previous chemotherapy (yes vs. no) & 1.58 & $1.07-2.34$ & 0.021 \\
Previous radiotherapy (yes vs. no) & 1.08 & $0.76-1.53$ & 0.667 \\
Albumin (per 1 g/dl increase) & 0.70 & $0.55-0.90$ & 0.006 \\
LDH (per 1 U/l increase) & 1.00 & $1.00-1.00$ & 0.001 \\
RLC (per 1\% increase) & 0.96 & $0.94-0.98$ & $<0.001$ \\
\hline
\end{tabular}

$\mathrm{B}, \mathrm{RNC}$

\begin{tabular}{llll}
\hline Variables & HR & 95\% CI & P-value \\
\hline Male vs. female gender & 0.87 & $0.63-1.22$ & 0.427 \\
Age (per 1 year increase) & 1.01 & $1.00-1.03$ & 0.053 \\
Hematological vs. solid tumors & 0.62 & $0.36-1.07$ & 0.086 \\
Previous chemotherapy (yes vs. no) & 1.60 & $1.08-2.36$ & 0.019 \\
Previous radiotherapy (yes vs. no) & 1.14 & $0.80-1.61$ & 0.473 \\
Albumin (per 1 g/dl increase) & 0.67 & $0.52-0.86$ & 0.001 \\
LDH (per 1 U/l increase) & 1.00 & $1.00-1.00$ & 0.001 \\
RNC (per 1\% increase) & 1.02 & $1.01-1.04$ & 0.001 \\
\hline
\end{tabular}

LDH, lactate dehydrogenase; RLC, relative lymphocyte count; RNC, relative neutrophil count; HR, hazard ratio; CI, confidence interval.

according to the reference values in our laboratory. The lower limit of RLC and the upper limit of RNC were 19 and $75 \%$, respectively. Among all patients, those with an RLC of $\geq 19 \%$ had significantly better overall survival compared with those with an RLC of $<19 \%(\mathrm{P}<0.001)$; this was also true for subgroups $A(P=0.040)$ and $B(P=0.016)$. Overall survival for all patients and subgroup B was significantly better for $\mathrm{RNC}<75 \%$ compared with $\mathrm{RNC} \geq 75 \%(\mathrm{P}<0.001$ and $\mathrm{P}=0.020$, respectively); the difference was not statistically significant in subgroup A $(\mathrm{P}=0.138)$.

ROC analysis was performed in 184 patients (84\%) who were followed up for $>5$ months or until death. Table IV shows the 

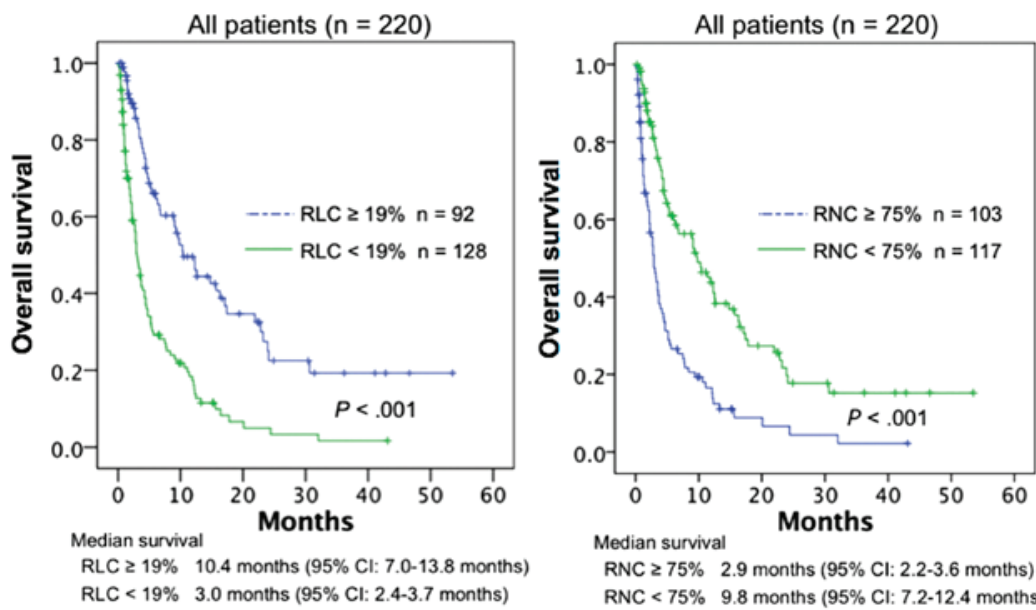

Median survival

RNC $\geq 75 \% \quad 2.9$ months ( $95 \% \mathrm{Cl}: 2.2-3.6$ months) RNC $<75 \% 9.8$ months (95\% Cl: 7.2-12.4 months)
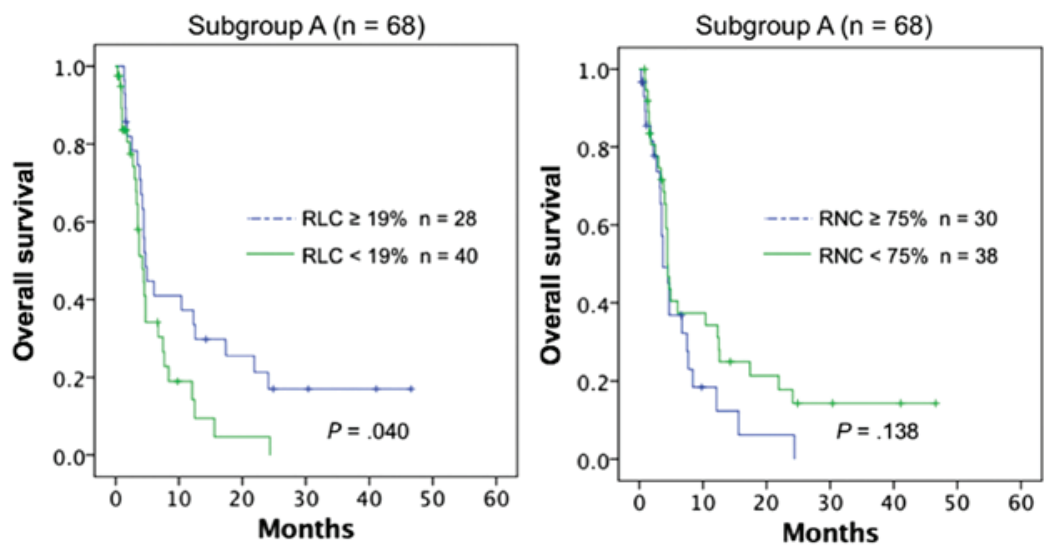

Median survival

RLC $\geq 19 \% 4.7$ months (95\% Cl: 3.9-5.5 months) RLC $<19 \% \quad 4.2$ months (95\% Cl: 3.0-5.4 months)

Median surviva

RNC $\geq 75 \% \quad 3.7$ months (95\% Cl: $2.6-4.8$ months) RNC $<75 \% \quad 4.4$ months ( $95 \%$ Cl: $3.9-4.9$ months)

Subgroup B $(n=49)$
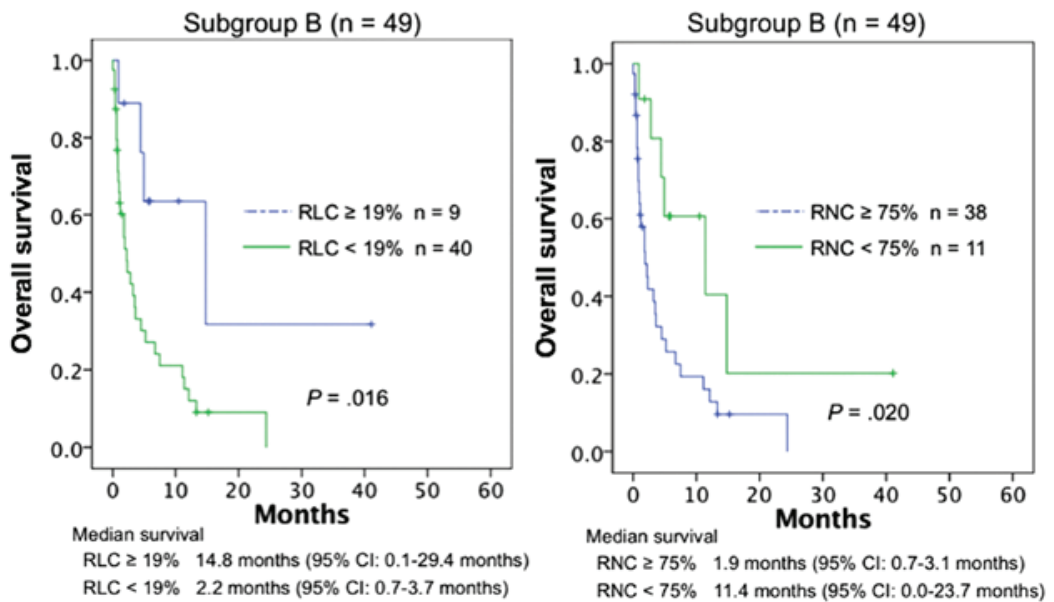

Figure 1. Overall survival based on relative lymphocyte and neutrophil counts. The continuous variables were dichotomized according to the reference values in our laboratory. The lower limit of RLC and the upper limit of RNC were 19 and 75\%, respectively. RLC, relative lymphocyte count; RNC, relative neutrophil count; CI, confidence interval; Subgroup A, patients who received chemotherapy within 1 month prior to blood sampling; subgroup B, patients who received steroids at the time of blood sampling.

AUC for the ROC curves for each WBC parameter. RLC and the $\mathrm{N} / \mathrm{L}$ and $\mathrm{L} / \mathrm{M}$ ratios were slightly better at predicting death within 5 months compared with the remaining 4 parameters.

\section{Discussion}

Of the seven WBC parameters investigated, RLC and RNC were of high prognostic value for the survival of patients receiving palliative RT. Overall, patients with low RLC and those with high RNC had poor overall survival; this was also true for patients receiving steroids or chemotherapy. The RLC value was a slightly better predictor, as its prognostic value was consistently significant in our subgroup analyses using the log-rank test, and its AUC value in the ROC curve analysis was higher.

Data on the prognostic value of parameters derived from WBC and differential counts in patients receiving palliative RT are limited. Gripp et al (25) found that an elevated TWBC 
Table IV. Receiver operating characteristic curve analysis to predict death within 5 months $(n=184)$.

\begin{tabular}{lccr}
\hline Variables & AUC & $95 \%$ CI & P-value \\
\hline TWBC & 0.625 & $0.532-0.717$ & 0.027 \\
ALC & 0.697 & $0.594-0.800$ & $<0.001$ \\
RLC & 0.777 & $0.694-0.861$ & $<0.001$ \\
ANC & 0.671 & $0.581-0.761$ & 0.002 \\
RNC & 0.727 & $0.635-0.819$ & $<0.001$ \\
N/L ratio & 0.766 & $0.680-0.851$ & $<0.001$ \\
L/M ratio & 0.774 & $0.691-0.858$ & $<0.001$ \\
\hline
\end{tabular}

TWBC, total white blood cell count; ALC, absolute lymphocyte count; RLC, relative lymphocyte count; ANC, absolute neutrophil count; RNC, relative neutrophil count; N/L ratio, neutrophil-to-lymphocyte ratio; $\mathrm{L} / \mathrm{M}$ ratio, lymphocyte-to-monocyte ratio; $\mathrm{AUC}$, area under the curve; $\mathrm{CI}$, confidence interval.

was associated with a poor prognosis in 216 patients recently referred for palliative RT. Others reported that decreased ALC values were a prognostic factor for poor survival in 104 patients with brain metastases who received whole-brain RT (26) and in 130 patients with brain metastases from breast cancer who received whole-brain RT (27). Survival prediction is critical for determining the dose fractionation schedule in patients receiving palliative RT $(1,2)$. Our findings may contribute to the identification of appropriate parameters for survival prediction in these patients.

Our subgroup analyses demonstrated that RLC and RNC were useful predictors of survival, even in patients receiving medications that affect WBC and differential counts. Certain patients receiving palliative RT are also treated with chemotherapy or steroids. Earlier studies on the prognostic value of WBC parameters excluded patients receiving steroids or chemotherapy $(14,24,28)$; our subgroup analysis renders our findings applicable to such patients.

WBC parameters have been shown to be of prognostic value in patients with various malignancies (9,12-24). Palliative RT is delivered to heterogeneous patient populations, i.e., patients with solid tumors from different primary sites and patients with hematological tumors. In such patients, disease-specific factors, such as tumor stage $(20,29-31)$, tumor size $(31,32)$, or tumor-specific markers (33-35) do not appear to be useful for the prediction of prognosis. However, RLC and RNC may represent useful prognostic factors in heterogeneous patients receiving palliative RT.

Our study had certain limitations. First, as it was retrospective, potential confounders, such as performance status, could not be included in the multivariate analysis. Furthermore, the size of the subgroups was limited and parameters other than RLC or RNC may be found to be of prognostic value in larger patient populations.

In summary, the prognostic value of seven WBC parameters was compared and low RLC and high RNC levels were found to predict poor survival in patients receiving palliative RT. Our subgroup analyses demonstrated that these were significant prognostic factors, even in patients treated with medications affecting WBC and differential counts. As the investigated parameters are derived from complete blood counts, they may be used in daily clinical practice. Our findings may contribute to the selection of appropriate treatment schedules for patients receiving palliative $\mathrm{RT}$.

\section{References}

1. Gripp S, Mjartan S, Boelke E and Willers R: Palliative radiotherapy tailored to life expectancy in end-stage cancer patients: Reality or myth? Cancer 116: 3251-3256, 2010.

2. Nieder C, Angelo K, Dalhaug A, Pawinski A, Haukland E and Norum J: Palliative radiotherapy during the last month of life: Predictability for referring physicians and radiation oncologists. Oncol Lett 10: 3043-3049, 2015.

3. Chow E, Abdolell M, Panzarella T, Harris K, Bezjak A, Warde P and Tannock I: Validation of a predictive model for survival in metastatic cancer patients attending an outpatient palliative radiotherapy clinic. Int J Radiat Oncol Biol Phys 73: 280-287, 2009.

4. Krishnan MS, Epstein-Peterson Z, Chen YH, Tseng YD, Wright AA, Temel JS, Catalano P and Balboni TA: Predicting life expectancy in patients with metastatic cancer receiving palliative radiotherapy: The TEACHH model. Cancer 120: 134-141, 2014.

5. Mizumoto M, Harada H, Asakura H, Hashimoto T, Furutani K, Hashii H, Takagi T, Katagiri H, Takahashi $\mathrm{M}$ and Nishimura T: Prognostic factors and a scoring system for survival after radiotherapy for metastases to the spinal column: A review of 544 patients at Shizuoka cancer center hospital. Cancer 113: 2816-2822, 2008.

6. Tseng YD, Krishnan MS, Sullivan AJ, Jones JA, Chow E and Balboni TA: How radiation oncologists evaluate and incorporate life expectancy estimates into the treatment of palliative cancer patients: A survey-based study. Int J Radiat Oncol Biol Phys 87: 471-478, 2013.

7. Mantovani A, Allavena P, Sica A and Balkwill F: Cancer-related inflammation. Nature 454: 436-444, 2008.

8. Colotta F, Allavena P, Sica A, Garlanda C and Mantovani A: Cancer-related inflammation, the seventh hallmark of cancer: Links to genetic instability. Carcinogenesis 30: 1073-1081, 2009.

9. Nagai S, Abouljoud MS, Kazimi M, Brown KA, Moonka D and Yoshida A: Peritransplant lymphopenia is a novel prognostic factor in recurrence of hepatocellular carcinoma after liver transplantation. Transplantation 97: 694-701, 2014.

10. Vaduganathan M, Ambrosy AP, Greene SJ, Mentz RJ, Subacius HP, Maggioni AP, Swedberg K, Nodari S, Zannad F, Konstam MA, et al: Predictive value of low relative lymphocyte count in patients hospitalized for heart failure with reduced ejection fraction: Insights from the EVEREST trial. Circ Heart Fail 5: 750-758, 2012.

11. Kovesdy CP, George SM, Anderson JE and Kalantar-Zadeh K: Outcome predictability of biomarkers of protein-energy wasting and inflammation in moderate and advanced chronic kidney disease. Am J Clin Nutr 90: 407-414, 2009.

12. Hyodo I, Morita T, Adachi I, Shima Y, Yoshizawa A and Hiraga K: Development of a predicting tool for survival of terminally ill cancer patients. Jpn J Clin Oncol 40: 442-448, 2010.

13. Jin Y, Ye X, He C, Zhang B and Zhang Y: Pretreatment neutrophil-to-lymphocyte ratio as predictor of survival for patients with metastatic nasopharyngeal carcinoma. Head Neck 37: 69-75, 2015.

14. De Giorgi U, Rihawi K, Aieta M, Lo Re G, Sava T, Masini C, Baldazzi V, De Vincenzo F, Camerini A, Fornarini G, et al: Lymphopenia and clinical outcome of elderly patients treated with sunitinib for metastatic renal cell cancer. J Geriatr Oncol 5: 156-163, 2014.

15. Le Scodan R, Massard C, Mouret-Fourme E, Guinebretierre JM, Cohen-Solal C, De Lalande B, Moisson P, Breton-Callu C, Gardner M, Goupil A, et al: Brain metastases from breast carcinoma: Validation of the radiation therapy oncology group recursive partitioning analysis classification and proposition of a new prognostic score. Int J Radiat Oncol Biol Phys 69: 839-845, 2007.

16. Kikuchi N, Ohmori K, Kuriyama S, Shimada A, Nakaho T, Yamamuro $M$ and Tsuji I: Survival prediction of patients with advanced cancer: The predictive accuracy of the model based on biological markers. J Pain Symptom Manage 34: 600-606, 2007. 
17. Schmidt H, Suciu S, Punt CJ, Gore M, Kruit W, Patel P, Lienard D, von der Maase H, Eggermont AM, Keilholz U, et al: Pretreatment levels of peripheral neutrophils and leukocytes as independent predictors of overall survival in patients with American joint committee on cancer stage IV melanoma: ReSults of the EORTC 18951 biochemotherapy trial. J Clin Oncol 25: 1562-1569, 2007.

18. Teramukai S, Kitano T, Kishida Y, Kawahara M, Kubota K, Komuta K, Minato K, Mio T, Fujita Y, Yonei T, et al: Pretreatment neutrophil count as an independent prognostic factor in advanced non-small-cell lung cancer: An analysis of Japan multinational trial organisation LC00-03. Eur J Cancer 45: 1950-1958, 2009.

19. He JR, Shen GP, Ren ZF, Qin H, Cui C, Zhang Y, Zeng YX and Jia WH: Pretreatment levels of peripheral neutrophils and lymphocytes as independent prognostic factors in patients with nasopharyngeal carcinoma. Head Neck 34: 1769-1776, 2012.

20. Absenger G, Szkandera J, Pichler M, Stotz M, Arminger F, Weissmueller M, Schaberl-Moser R, Samonigg H, Stojakovic T and Gerger A: A derived neutrophil to lymphocyte ratio predicts clinical outcome in stage II and III colon cancer patients. Br J Cancer 109: 395-400, 2013.

21. Templeton AJ, Pezaro C, Omlin A, McNamara MG, Leibowitz-Amit R, Vera-Badillo FE, Attard G, de Bono JS, Tannock IF and Amir E: Simple prognostic score for metastatic castration-resistant prostate cancer with incorporation of neutrophil-to-lymphocyte ratio. Cancer 120: 3346-3352, 2014.

22. Szkandera J, Gerger A, Liegl-Atzwanger B, Absenger G, Stotz M, Friesenbichler J, Trajanoski S, Stojakovic T, Eberhard K, Leithner A and Pichler M: The lymphocyte/monocyte ratio predicts poor clinical outcome and improves the predictive accuracy in patients with soft tissue sarcomas. Int J Cancer 135 362-370, 2014

23. Rambaldi A, Boschini C, Gritti G, Delaini F, Oldani E, Rossi A, Barbui AM, Caracciolo D, Ladetto M, Gueli A, et al: The lymphocyte to monocyte ratio improves the IPI-risk definition of diffuse large B-cell lymphoma when rituximab is added to chemotherapy. Am J Hematol 88: 1062-1067, 2013.

24. Huang Y and Feng JF: Low preoperative lymphocyte to monocyte ratio predicts poor cancer-specific survival in patients with esophageal squamous cell carcinoma. Onco Targets Ther 8: 137-145, 2015.

25. Gripp S, Moeller S, Bölke E, Schmitt G, Matuschek C, Asgari S, Asgharzadeh F, Roth S, Budach W, Franz M and Willers R: Survival prediction in terminally ill cancer patients by clinical estimates, laboratory tests and self-rated anxiety and depression. J Clin Oncol 25: 3313-3320, 2007.
26. Claude L, Perol D, Ray-Coquard I, Petit T, Blay JY, Carrie C and Bachelot T: Lymphopenia: A new independent prognostic factor for survival in patients treated with whole brain radiotherapy for brain metastases from breast carcinoma. Radiother Oncol 76 334-339, 2005.

27. Le Scodan R, Massard C, Jouanneau L, Coussy F, Gutierrez M, Kirova Y, Lerebours F, Labib A and Mouret-Fourme E: Brain metastases from breast cancer: Proposition of new prognostic score including molecular subtypes and treatment. J Neurooncol 106: $169-176,2012$.

28. Keizman D, Ish-Shalom M, Huang P, Eisenberger MA, Pili R, Hammers $\mathrm{H}$ and Carducci MA: The association of pre-treatment neutrophil to lymphocyte ratio with response rate, progression free survival and overall survival of patients treated with sunitinib for metastatic renal cell carcinoma. Eur J Cancer 48: 202-208, 2012.

29. Loghavi S, Alayed K, Aladily TN, Zuo Z, Ng SB, Tang G, Hu S, Yin CC, Miranda RN, Medeiros LJ and Khoury JD: Stage, age, and EBV status impact outcomes of plasmablastic lymphoma patients: A clinicopathologic analysis of 61 patients. J Hematol Oncol 8: 65, 2015.

30. Kao SC, Vardy J, Chatfield M, Corte P, Pavlakis N, Clarke C, van Zandwijk $\mathrm{N}$ and Clarke S: Validation of prognostic factors in malignant pleural mesothelioma: A retrospective analysis of data from patients seeking compensation from the New South Wales dust diseases board. Clin Lung Cancer 14: 70-77, 2013.

31. Han LH, Jia YB, Song QX, Wang JB, Wang NN and Cheng YF: Prognostic significance of preoperative lymphocyte-monocyte ratio in patients with resectable esophageal squamous cell carcinoma. Asian Pac J Cancer Prev 16: 2245-2250, 2015

32. Deng J, Zhang R, Pan Y, Ding X, Cai M, Liu Y, Liu H, Bao T, Jiao $\mathrm{X}$, Hao $\mathrm{X}$ and Liang $\mathrm{H}$ : Tumor size as a recommendable variable for accuracy of the prognostic prediction of gastric cancer: A retrospective analysis of 1,521 patients. Ann Surg Oncol 22: 565-572, 2015.

33. Park JW, Lim SB, Kim DY, Jung KH, Hong YS, Chang HJ, Choi HS and Jeong SY: Carcinoembryonic antigen as a predictor of pathologic response and a prognostic factor in locally advanced rectal cancer patients treated with preoperative chemoradiotherapy and surgery. Int J Radiat Oncol Biol Phys 74: 810-817, 2009.

34. Hotta T, Takifuji K, Yokoyama S, Matsuda K, Oku Y, Nasu T, Ieda J, Yamamoto N, Iwamoto H, Takei Y, et al: Impact of the post/preoperative serum CEA ratio on the survival of patients with rectal cancer. Surg Today 44: 2106-2115, 2014.

35. Davidson NG, Khanna S, Kirwan PH and Bircumshaw D: Prechemotherapy serum CA125 level as a predictor of survival outcome in epithelial carcinoma of the ovary. Clin Oncol (R Coll Radiol) 3: 32-36, 1991. 